\title{
NMDA-induced lesions of the amygdaloid complex block the retention-enhancing effect of posttraining epinephrine
}

\author{
LARRY CAHILL and JAMES L. MCGAUGH \\ University of California, Irvine, California
}

\begin{abstract}
Rats with either bilateral amygdaloid complex (AC) lesions (produced by injection of the excitotoxin NMDA) or control surgery were trained on a one-trial step-through inhibitory-avoidance task and given immediate posttraining injections of either epinephrine $(100 \mu \mathrm{g} / \mathrm{kg}$, i.p. $)$ or saline. Epinephrine significantly enhanced retention performance (measured $24 \mathrm{~h}$ after training) in rats that received the control surgery. The enhancement was completely blocked, however, in the AClesioned subjects. Furthermore, the lesions themselves significantly impaired learning of the task. The results are discussed in the context of evidence suggesting that the $\mathrm{AC}$ is involved in mediating the effects of endogenous hormones on memory processes.
\end{abstract}

It is well established that injections of drugs or hormones administered to animals soon after training in a variety of learning tasks can alter later retention performance. Such findings are usually interpreted as indicating that the treatments influence performance by altering memory storage processes (Gold \& McGaugh, 1977; McGaugh, 1983, 1989a). The fact that hormones can enhance retention when administered in physiological doses suggests the hormones may be part of an endogenous memory-modulating system. That is, hormones released by training experiences may function to modulate the memory for those experiences (Gold \& McGaugh, 1977; McGaugh, 1989b; McGaugh \& Gold, 1989). Gold and van Buskirk's initial (1975) report that, in rats, posttraining systemic injections of epinephrine enhance retention of an inhibitory-avoidance response has been confirmed by many studies that used a variety of training tasks, including active avoidance, discrimination, and appetitively motivated tasks (McGaugh \& Gold, 1989). Such findings have provided compelling evidence supporting the view that epinephrine modulates memory storage (McGaugh, 1989b).

There is extensive evidence suggesting that epinephrine, as well as other treatments affecting neuromodulatory systems, modulates memory storage through influences involving the amygdaloid complex (AC). Lesions of the stria terminalis, a major AC pathway, attenuate the enhancing effect of posttraining systemic injections of epinephrine and clenbuterol, a $\beta$-adrenergic agonist, on retention of an inhibitory-avoidance task (Introini-Collison, Miya-

\footnotetext{
This research was supported by Grant USPHS MH12526 from the NIMH and the NIDA and by ONR Contract NO0014-87-K-0518. Correspondence should be addressed to James L. McGaugh, Center for the Neurobiology of Learning and Memory, University of California, Irvine, CA 92717.
}

zaki, \& McGaugh, in press; Liang \& McGaugh, 1983). Stria terminalis lesions also attenuate memory-modulating effects of naloxone and $\beta$-endorphin, as well as the effects of cholinergic drugs (Introini-Collison, Arai, \& McGaugh, 1989; McGaugh, Introini-Collison, Juler, \& Izquierdo, 1986). Other investigators have reported that AC lesions block the inhibitory effects of vasopressin and ACTH4-10 on extinction of active avoidance behavior (Van Wimersma Greidanus, Croiset, Bakker, \& Bouman, 1979). AC lesions also block the memory-modulating effects of posttraining administration of GABAergic drugs (Ammassari-Teule, Pavone, Castellano, \& McGaugh, 1991). AC involvement in the modulatory influences of hormones on memory is further suggested by the finding that intraamygdala injections of adrenergic antagonists block the memory-enhancing effect of epinephrine and naloxone (Introini-Collison, Nagahara, \& McGaugh, 1989; Liang, Juler, \& McGaugh, 1986; McGaugh, Introini-Collison, \& Nagahara, 1988).

Thus, converging evidence suggests that an intact AC is required for posttraining hormonal injections to exert modulating effects on memory storage. As a further examination of this hypothesis, the present experiment investigated the effects of posttraining systemic injections of epinephrine in animals with lesions of the AC. Bilateral lesions were made by injections of the excitatory amino acid N-methyl-D-aspartic acid (NMDA), which destroys cell bodies but spares fibers of passage (Stewart, Price, Olney, Hartman, \& Cozzari, 1986).

\section{METHOD}

\section{Subjects}

Male Sprague-Dawley rats, 60-70 days old and weighing 250-275 $\mathrm{g}$ on arrival, were individually housed and maintained on a 12:12-h light:dark cycle (lights on at 7:00 a.m.). Food and water were available ad lib. 


\section{Surgery}

Approximately one week after arrival, rats received stereotaxic surgery under sodium pentobarbital anesthesia $(50-60 \mathrm{mg} / \mathrm{kg}$, i.p.). To produce the lesions, NMDA (Sigma Chemical; $10 \mu \mathrm{g} / \mu \mathrm{l} 0.9 \%$ saline) was backfilled into a 30-ga needle connected via water-filled polyethylene tubing to a 5- $\mu \mathrm{l}$ Hamilton microsyringe. The cannula were stereotaxically placed into the $\mathrm{AC}$ (coordinates from bregma: AP -2.2; ML $\pm 4.4 ; \mathrm{DV}-8.0$, nose bar at -3.3 ). For each injection, $6 \mu \mathrm{g}$ NMDA (in $0.6 \mu \mathrm{l}$ ) was injected over a 2 -min interval with a syringe pump (Sage Instruments). The needle was retained in the brain for an additional 3-5 min following injection in order to maximize diffusion away from the needle tip. After both injections were complete, the burr holes were sealed with bone wax and the scalp incision closed with wound clips. Each rat then received both penicillin $(0.1 \mathrm{cc}, \mathrm{i} . \mathrm{m}$.) and $0.9 \%$ saline $(2 \mathrm{cc}$, i.p.) to facilitate recovery. The control-surgery rats received the same treatment, except the needle was lowered only to the level of the caudate-putamen, just dorsal to the $\mathrm{AC}$, and removed.

\section{Behavioral Testing}

Approximately one week after surgery, the rats were trained in a one-trial inhibitory-avoidance task (McGaugh et al., 1988). The apparatus was a trough-shaped alley divided by a sliding door into two compartments: one illuminated, one darkened. The rat was placed into the lighted side facing the closed door, and the door was opened when the rat turned away from it. When it turned back toward the door, a timer was started, and, as the rat entered the darkened side, the timer was stopped, the door closed, and a brief shock was delivered $(0.7 \mathrm{sec}, 0.35 \mathrm{~mA}, 60 \mathrm{~Hz}$; Lafayette Instrument). This low-intensity shock level was chosen so that the controls would demonstrate relatively short retention latencies. This was essential to avoid ceiling effects that would obscure retention enhancement. Immediately after training, the rats were removed from the apparatus, injected, and returned to their home cages. Twenty-four hours later, the rats were placed in the lighted compartment, as in training. The latency (maximum of $300 \mathrm{sec}$ ) to enter the darkened compartment was used as the index of retention. All testing was conducted between 1:00 and 5:00 p.m.

\section{Drug Administration}

All rats received either saline or epinephrine $(100 \mu \mathrm{g} / \mathrm{kg}$, i.p.) immediately after training. The dose was chosen on the basis of numerous prior studies in this laboratory (Gold \& van Buskirk, 1975; Liang \& McGaugh, 1983) that demonstrated reliable memoryenhancing effects at this dose in the inhibitory-avoidance task. Epinephrine was prepared by dilution from a $1-\mathrm{ml} / \mathrm{kg}$ solution (containing $0.1 \%$ sodium bisulfite; Elkins-Sinn Inc.) with $0.9 \%$ saline to $100 \mu \mathrm{g} / \mathrm{ml}$. All injection volumes were $1 \mathrm{ml} / \mathrm{kg}$.

\section{Histology}

At the conclusion of the experiment, the rats were sacrificed with an overdose of sodium pentobarbital and perfused through the heart with saline followed by $10 \%$ formalin. The brain was removed and placed in formalin for at least 3 days. Each brain was then placed in $20 \%$ sucrose $10 \%$ formalin for 1-2 days, sectioned on a freezing microtome, and stained with cresyl violet. Sections were then examined microscopically to determine the extent of the lesion. Diagrams of the maximal extent of each lesion were transferred to standardized atlas plates (Paxinos \& Watson, 1986). Animals were excluded from subsequent analysis if the observed lesions were judged too small or too irregular, or if the lesion placement was inaccurate.

\section{RESULTS}

\section{Histology}

NMDA injections produced the characteristic damage that is seen with excitotoxins: a loss of neurons accom- panied by extensive gliosis in the affected regions. Typically, the lesions involved all or part of the lateral, basolateral, basomedial, medial, and cortical nuclei, as well as the intercalated amygdaloid nuclei. Additional damage was occasionally seen in the most ventral portions of the caudate nucleus and the piriform cortex. Consistent with the reports of other investigators, NMDA did not appear to produce any "distant damage" in other structures, such as the hippocampus, as is commonly seen following kainic acid injections (Numan, Corodimas, Numan, Factor, \& Piers, 1988; Stewart et al., 1986). In 12 of 26 lesioned subjects, small, irregular-shaped cavities were seen in the area of the injection needle tip. This finding is comparable to that reported by Jellestad and Cabrera (1986) in an experiment in which they lesioned the AC by using ibotenic acid (which also acts at the NMDA receptor). In the regions in which cavities were observed, fibers-of-passage were clearly destroyed. Also consistent with previous reports was the finding that damage to the central nucleus (CE) was substantial but quite variable (Dunn \& Everitt, 1988; Jellestad \& Cabrera, 1986). In 7 subjects, the CE was destroyed bilaterally, and in 6 more, unilateral destruction was seen. In 6 cases, however, the lesion stopped abruptly at the border of the central nucleus. This phenomenon may be explained either by the existence of fiber tracts that present a barrier to the diffusion of the NMDA into the central nucleus or by the relatively sparse distribution of NMDA receptors in the central nucleus (Monaghan \& Cotman, 1985). Representations of both the smallest and the largest lesions included in this study, as well as an average-size lesion, are shown in Figure 1.

\section{Behavioral Testing}

The results for all four experimental groups, expressed as the median entry latencies (and interquartile ranges) on the retention test, are shown in Figure 2. The scores of control subjects given posttraining epinephrine were significantly higher than those of rats given saline $(U=$ 97, $p<.05$; two-tailed Mann-Whitney $U$ test). However, epinephrine did not affect retention in the AClesioned rats. The retention latencies of lesioned rats given epinephrine after training were comparable to those given saline. Furthermore, the $\mathrm{AC}$ lesion alone significantly impaired retention. In AC-lesioned rats, the retention latencies of both the saline- and the epinephrine-injected rats were significantly shorter than those of the saline-injected controls $(U=38.5$ for control/saline compared with lesion/saline, $U=35$ compared with lesion/epinephrine; $p<.005$ for both).

\section{DISCUSSION}

These findings indicate that NMDA-induced lesions of the $\mathrm{AC}$ block the enhancing effect of posttraining epinephrine on retention of an inhibitory-avoidance response. Thus, these results provide additional support for the view that the integrity of AC circuitry is required for hormonal influences on memory (Liang \& McGaugh, 1983; Van 


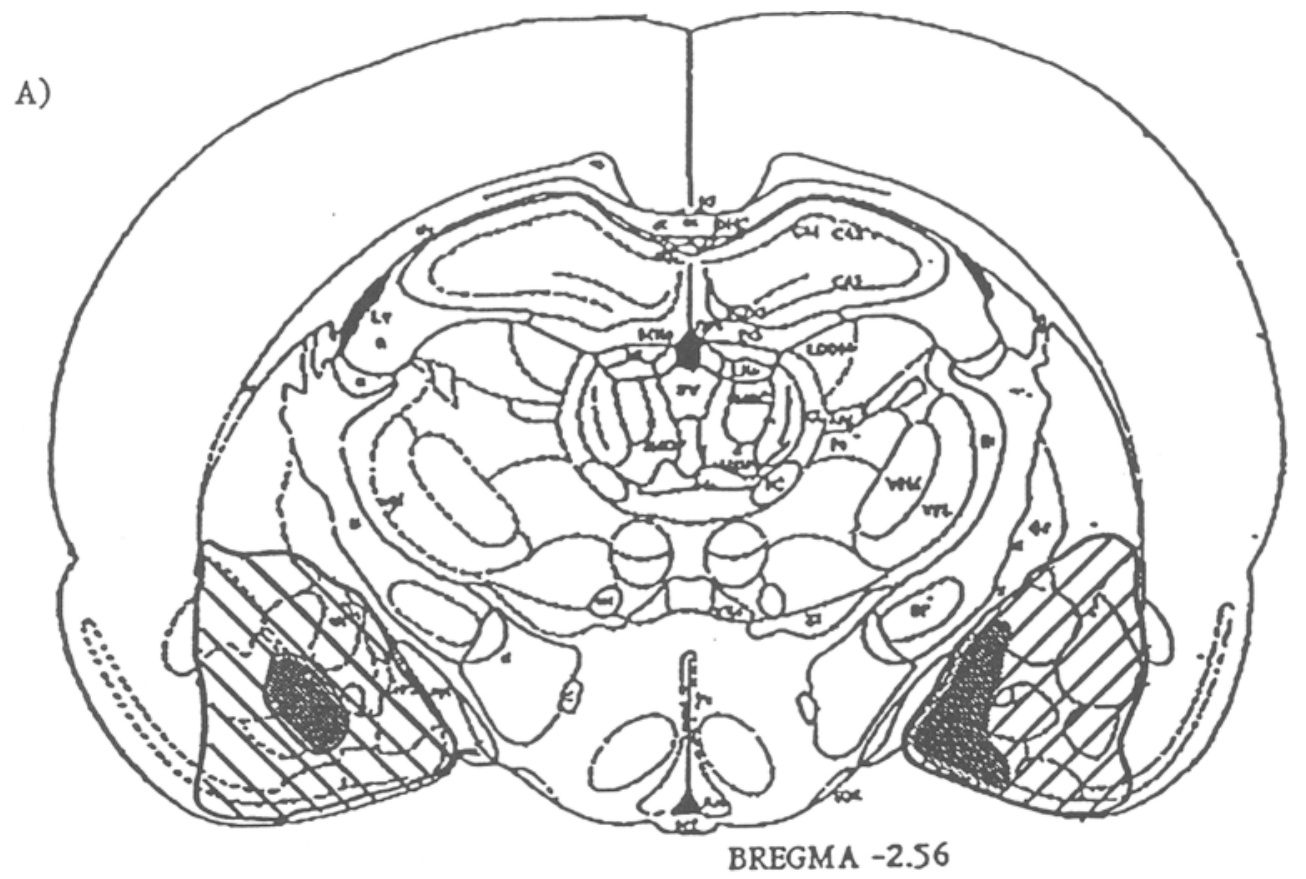

B)

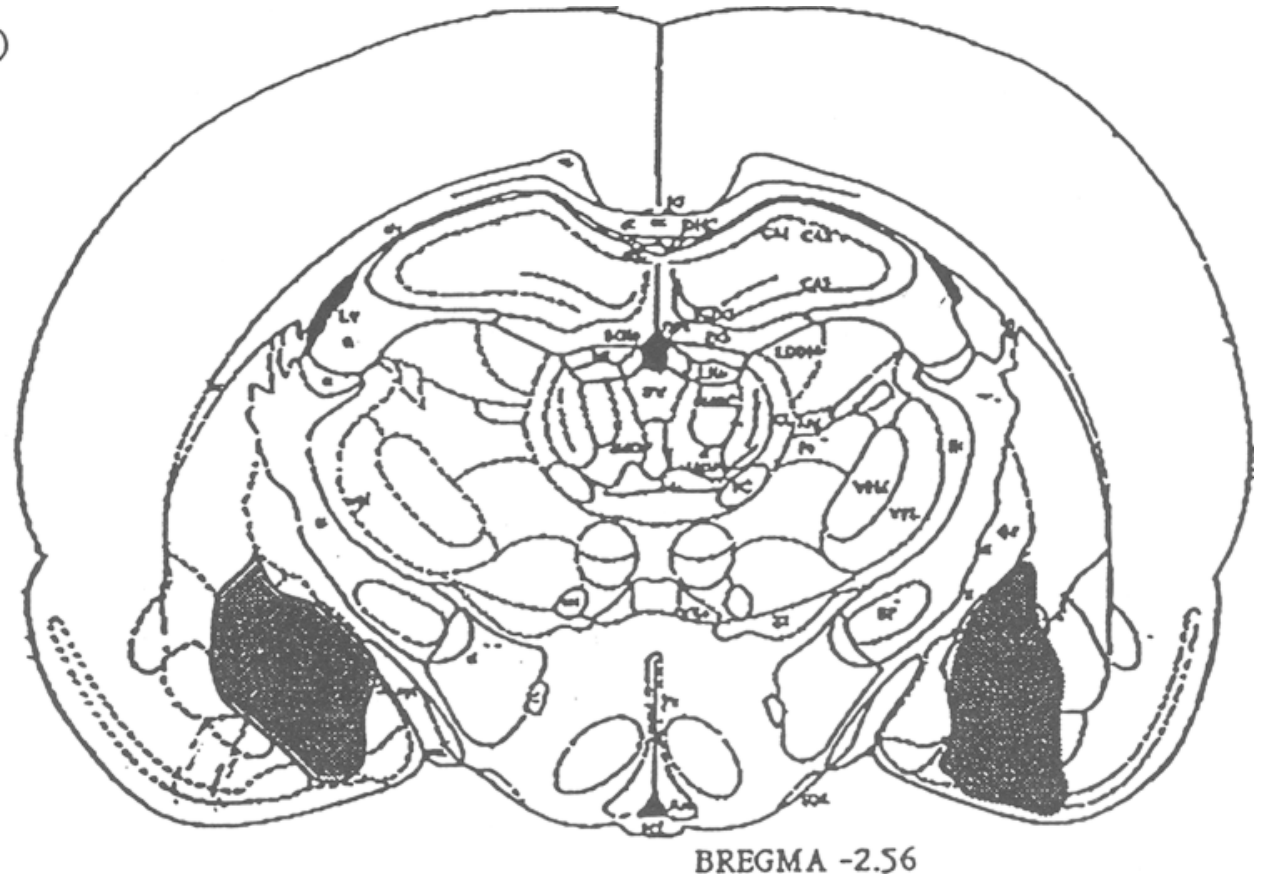

Figure 1. (A) Shows the largest (cross-hatched) and smallest (darkened) lesions included in this study; (B) shows an average-size lesion (darkened). Representations are at the level of maximal damage. Atlas plates taken from Paxinos and Watson, 1986. 


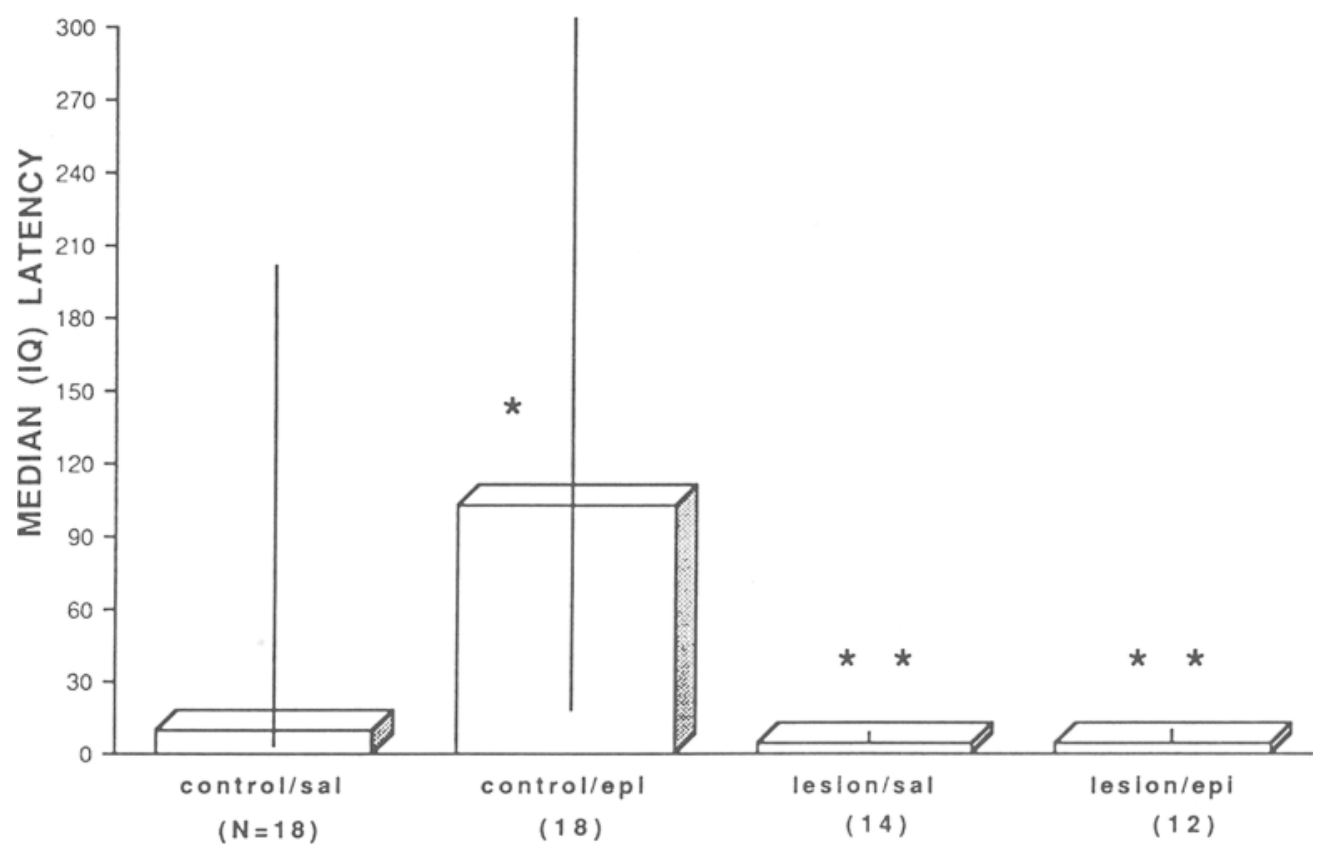

Figure 2. Effects of NMDA-amygdala lesions on epinephrine-induced enhancement of kearning. All groups received either epinephrine $(100 \mathrm{\mu g} / \mathrm{kg}$, i.p.) or physiological saline immediately after a single training trial and were tested for retention $24 \mathrm{~h}$ later. Error bars indicate interquartile ranges. *Different from control/sal group ( $p<.05)$. ** Different from control/sal group $(p<.005)$.

Wimersma Greidanus et al., 1979). The dose of epinephrine that was used in this study was chosen because it was found to be optimal in producing enhancement of retention of an inhibitory-avoidance response (Liang \& McGaugh, 1983). Liang and McGaugh (1983) reported that doses of epinephrine both higher and lower than that used in this study (by $1 \log$ unit) also produced significant retention enhancement. Thus, it seems unlikely that the lack of effect of epinephrine in the lesioned rats in this study was due simply to a lesion-induced shift in the dose-response effect of epinephrine. However, it remains possible that the amygdala lesion might narrow the range of doses that is effective in producing a memory-enhancing effect.

Compared with the controls, the NMDA-induced lesions significantly impaired retention performance. It is unlikely that this deficit was due to a decreased sensitivity to footshock, as we have found that NMDA-induced lesions of the $\mathrm{AC}$ do not alter thresholds for reaction to footshock (Cahill \& McGaugh, 1989). These findings are consistent with other evidence indicating that extensive AC lesions impair inhibitory-avoidance learning (Cahill \& McGaugh, 1990; Jellestad \& Bakke, 1985; Pellegrino, 1968). In contrast, lesions of the stria terminalis do not impair inhibitory-avoidance learning but do block the memory-enhancing effects of peripheral hormones (Liang \& McGaugh, 1983; McGaugh et al., 1986). Clearly, such findings suggest that the learning impairment induced by amygdala lesions are not due solely to the blocking of modulating influences on memory storage. In view of the short retention latencies of the AC-lesioned animals, it is possible that the degree of learning in these animals was simply not sufficient to enable modulating influences. However, we have found significant memory-enhancing effects of drugs in other experiments in which controls had retention latencies somewhat comparable to those of the lesioned controls in the present experiment (Brioni, Nagahara, \& McGaugh, 1989; Introini-Collison, Miyazaki, \& McGaugh, in press).

Because epinephrine crosses the blood-brain barrier poorly, if at all (Weil-Malherbe, Axelrod, \& Tomchick, 1959), it is unlikely that the hormone enhances retention by acting directly on cells in the AC. Rather, it seems more likely that epinephrine activates peripheral receptors, which in turn affect the pronounced visceral afferent information to the AC (especially its central nucleus) from the brainstem (De Olmos, Alheid, \& Beltramino, 1985). This view is consistent with recent findings indicating that epinephrine's effects on memory are blocked by sotalol, a peripherally acting $\beta$-adrenergic antagonist (Introini-Collison \& McGaugh, 1991). But whatever the mechanism(s), our findings clearly support a role for the AC in mediating hormonal effects on memory. More generally, they strengthen the conclusion that the $A C$ is involved in regulating the storage of recently acquired in- 
formation and suggest that such regulation is influenced, at least in part, by experiences that initiate the release of stress-related hormones.

\section{REFERENCES}

Ammassari-Teule, M., Pavone, F., Castellano, C., \& McGaugh, J. L. (1991). Amygdala and dorsal hippocampus lesions block the effects of GABAergic drugs on memory storage. Brain Research, 551, 104-109.

Brioni, J. D., Nagahara, A. H., McGaugh, J. L. (1989). Involvement of the amygdala GABAergic system in the modulation of memory storage. Brain Research, 487, 105-112.

CAHILL, L., \& MCGAUGH, J. L. (1989). [Effect of NMDA lesions of the amygdala in inhibitory avoidance.] Unpublished raw data.

CAHILL, L., \& MCGAUGH, J. L. (1990). Amygdaloid complex lesions differentially affect retention of tasks using appetitive and aversive reinforcement. Behavioral Neuroscience, 104, 532-543.

De Olmos, J., Alhem, G. F., \& Beltramino, C. A. (1985). Amygdala. In G. Paxinos (Ed.), The rat nenous system (pp. 223-317). New York: Academic Press.

DunN, L. T., \& Everitr, B. J. (1988). Double dissociations of the effects of amygdala and insular cortex lesions on conditioned taste aversion, passive avoidance, and neophobia on the rat using the excitotoxin ibotenic acid. Behavioral Neuroscience, 102, 3-23.

Gold, P. E., McGAUGH, J. L. (1977). Hormones and memory. In L. H. Miller, C. A. Sandman, \& A. J. Kastin (Eds.), Neuropeptide influences on brain and behavior (pp. 127-143). New York: Raven Press.

Gold, P. E., VAN BUSKIRK, R. B. (1975). Facilitation of timedependent memory processes with posttrial epinephrine injections. Behavioral Biology, 13, 145-153.

Introini-Collison, I. B., Aral, Y., \& McGaugh, J. L. (1989). Stria terminalis lesions attenuate the effects of posttraining oxotremorine and atropine on retention. Psychopharmacology, 17, 397-401.

InTroini-Coluson, I. B., * MCGAUGH, J. L. (1991). Interaction of hormones and neurotransmitter systems in the modulation of memory storage. In R. C. A. Frederickson, J. L. McGaugh, \& D. L. Felten (Eds.), Peripheral signaling of the brain: Role in neural-immune interactions, learning and memory (pp. 275-302). Toronto: Hogrefe \& Huber.

Introini-Coluson, I. B., Mryazakd, B., \& McGaugh, J. L. (in press). Involvement of the amygdala in the memory-enhancing effects of clenbuterol. Psychopharmacology.

Introini-Collison, I. B., Nagahara, A. H., McGaugh, J. L. (1989). Memory enhancement with intra-amygdala posttraining naloxone is blocked by concurrent administration of propranolol. Brain Research, 476, 94-101.

Jellestad, F. K., * BAKKE, H. K. (1985). Passive avoidance after ibotenic acid and radio-frequency lesions in the rat amygdala. Physiology \& Behavior, 34, 299-305.

Jellestad, F. K., \& CABRerA, I. C. (1986). Exploration and avoidance learning after ibotenic acid and radio-frequency lesions in the rat amygdala. Behavioral \& Neural Biology, 46, 196-215.
Liang, K. C., Juler, R. G., \& McGaugh, J. L. (1986). Modulating effects of post-training epinephrine on memory: Involvement of the amygdala noradrenergic system. Brain Research, 368, 125-133.

Liang, K. C., \& McGaugh, L. (1983). Lesions of the stria terminalis attenuate the enhancing effect of post-training epinephrine on retention of an inhibitory avoidance response. Behavioral Brain Research, 9, 49-58.

McGaugh, J. L. (1983). Hormonal influences on memory. Annual Review of Psychology, 34, 297-323.

MCGAUGH, J. L. (1989a). Dissociating learning and performance: Drug and hormone enhancement of memory storage. Brain Research Bulletin, 23, 339-345.

MCGAUGH, J. L. (1989b). Modulation of memory storage processes. In P. R. Solomon, G. R. Goethals, C. M. Kelley, \& B. R. Stephens (Eds.), Memory: Interdisciplinary approaches (pp. 33-64). New York: Springer-Verlag.

McGAUGH, J. L., \& GoLD, P. E. (1989). Hormonal modulation of memory. In R. B. Brush \& S. Levine (Eds.), Psychoendocrinology (pp. 305-339). New York: Academic Press.

MCGaugh, J. L., Introini-Collison, I. B., Juler, R. G., * IZqUiERDo, I. (1986). Stria terminalis iesions attenuate the effects of naloxone and $\beta$-endorphin on retention. Behavioral Neuroscience, 100 , 839-844.

MCGaugh, J. L., Introini-Collison, I. B., \& Nagahara, A. (1988). Memory-enhancing effects of post-training naloxone: Involvement of $\beta$-adrenergic influences in the amygdaloid complex. Brain Research, 446, 37-49.

Monaghan, D. T., Cotman, C. W. (1985). Distribution of N-methylD-aspartate-sensitive 1-[3H] Glutamate-binding sites in rat brain. Journal of Neuroscience, 5, 2909-2919.

Numan, M., Corodimas, K. P., Numan, M. J., Factor, E. M., \& PIERs, W. D. (1988). Axon-sparing lesions of the preoptic region and substantia innominata disrupt maternal behavior in rats. Behavioral Neuroscience, 102, 381-396.

Paxinos, G., W W Atson, C. (1986). The rat brain in stereotaxic coordinates. Orlando, FL: Academic Press.

Pellegrino, L. (1968). Amygdaloid lesions and behavioral inhibition in the rat. Journal of Comparative \& Physiological Psychology, 65, 483-491.

Stewart, G. R., Price, M., Olney, J. W., Hartman, B. K., \& Cozzaru, C. (1986). N-methylaspartate: An effective tool for lesioning basal forebrain cholinergic neurons of the rat. Brain Research, 369, 377-382.

Van Wimersma Greidanus, T., Croiset, G., Bakker, E., Bouman, H. (1979). Amygdaloid lesions block the effect of neuropeptides (vasopressin, ACTH4-10) on avoidance behavior. Physiology \& Behavior, 22, 291-295.

Weil-Malherbe, H., AXelrod, J., Tomchick, R. (1959). Bloodbrain barrier for adrenalin. Science, 129, 1226-1228.

(Manuscript received September 25, 1989; revision accepted for publication May 21, 1991.) 